\title{
Septorhinoplasty by disarticulation: Early assessment of a new technique for morphological correction of crooked noses*
}

\author{
N. Boulanger', C. Baumann², R. Beurton³, H. Elueque1, P. Gallet', \\ R. Grosjean', P. Lindas' ${ }^{3}$ C. Lorentz'1, R. Jankowski' \\ ' Service d'ORL et de chirurgie cervico-faciale, CHU NANCY Hôpital Central, Nancy, France \\ 2 Epidémiologie et Evaluation Cliniques, Centre d'épidémiologie clinique INSERM CIE6, CHU NANCY, Hôpitaux de Brabois, \\ Vandoeuvre-les-Nancy, France \\ ${ }^{3}$ Hôpitaux privés de Metz Ste Blandine, Metz, France
}

Rhinology 51:000-000, 2013 DOI:10.4193/Rhino12.147

*Received for publication: September 10, 2012

Accepted: December 31, 2012

\section{Summary}

Objective: This study was aimed to assess the early morphological results of a new septorhinoplasty technique based on disarticulation (SRD) between bony and cartilaginous nose structures.

Methodology: A retrospective, multi-judge, blind comparison of pre- and post-operative photographs displayed on Google documents ${ }^{\ominus}$ was designed. A nasal morphology analysis grid based on 10 items was fulfilled independently by 6 judges to assess pre- and post-operatively, two times with a 15 day interval, the severity of each deformity by a score between 0 and 2 . The sum of all deformities in a single patient produced the individual global score of nasal deformity, which was set between 0 and 20 for each patient. Pre- and post-operative individual global scores were compared using Student's t test on paired samples. Percentages of post-operative improvement and deterioration were calculated for each item.

Results: Thirty-five SRD were analyzed. Before surgery, $80 \%$ of noses were humped and $86 \%$ were crooked; three months after surgery, $64 \%$ of noses had a rectilinear nasal crest on profile and $57 \%$ on facial view. The mean global score of deformities dropped from 11.1 before surgery to 5.8 after surgery, an improvement of $47 \%$. Improvement rates of $82 \%$ and $74.3 \%$ were obtained, respectively, for hump profiles and orbitonasal lines.

Discussion: The early morphological results of SRD allow to propose this technique as a possible solution to correct crooked noses with humps.

Key words: rhinoplasty, septum nasal surgery, nasal cartilages, nasal bones, nose deformities

\section{Introduction}

There are currently two completely different methods of rhinoplasty for correcting nasal pyramid deformations; those derived from osteo-cartilaginous resection of the nasal dorsum described by Joseph in $1904{ }^{(1)}$, and those based on preservation of the dorsum, as described by Cottle in $1947^{(2)}$.

Joseph's rhinoplasty is the reference technique for correcting hump deformities, whilst Cottle's septoplasty is the reference technique for correcting functional deformities of the nasal septum.

However, the two techniques were never combined because osteo-cartilaginous resection of the nasal hump prevents complete disarticulation of the septal cartilage from its attachment on the perpendicular plate of the ethmoid bone and the vomer, 
an essential step in Cottle septoplasty. Indeed, once the septal cartilage is completely detached from its posterior and inferior edges, as performed in Cottle septoplasty, it can no longer be separated from the upper lateral cartilages as performed in nasal hump resection. This would involve total detachment with major risk of post-operative saddling and, moreover, stenosis of the internal nasal valve due to the collapse of the upper lateral cartilages.

Septorhinoplasty by disarticulation (SRD) proposes a solution to combine the two techniques: after Cottle septoplasty has been performed, the septo-lateral cartilage is dissected free of the piriform aperture; only the bony hump is resected and the open roof closed via lateral osteotomies; the preserved septolateral unit is then realigned under the new bony dorsum.

The objective of this work was to assess the early morphological results (3 months) after SRD in a retrospective, comparative study involving six judges (six surgeons) who separately and independently fulfilled the same nasal morphology analysis grid for each set of photographs, after all the pre- and post-operative photographs of all patients had been anonimized and randomly sorted out.

\section{Patients and methods}

\section{Study design}

A retrospective, comparative, blind, randomized, multi-judge study of patient's pre- and post-operative photographs.

\section{Description of the septorhinoplasty by disarticulation technique}

The septorhinoplasty by disarticulation (SRD) is performed in six consecutive steps:

Step 1: Nasal septum correction according to Cottle's principles: (Figure 1).

- Hemitransfixion incision parallel to and $2 \mathrm{~mm}$ behind the anterior edge of the septal cartilage

- Sub-perichondral and sub-periosteal elevation of the mucosa on both surfaces of the osteo-cartilaginous skeleton from the nasal floor to the dorsum and from its anterior edge to the posterior vomer edge and sphenoid rostrum

- Backward dissection of a small and blind columella pocket behind the medial crura of the alar cartilages

- Complete disarticulation of the inferior and posterior sutures between the septal cartilage and the bony vomeroethmoid framework

- Partial resection of vomer and ethmoidal perpendicular plate to widen the bony framework and release the reversible deformities of the septal cartilage, which were constrained by the bony framework (Figure 2)

- Resection of the non-reversible cartilaginous deformities, which are often fixed, angular deformities located at the inferior and posterior edges of the septal cartilage (Figure 3)

- Traction at the antero-inferior angle of the cartilage (Figure 3 and 4) to reposition it on the premaxilla, a manoeuvre that: 1) corrects any retro-lobular saddling induced by the septal cartilage disarticulation and 2) helps to adjust cartilage's anterior height to the desired new position of the cartilaginous dorsum and 3 ) helps to decide on the amount of anterior edge resection required for the cartilage to fit into the columellar pocket created just behind the medial crura (Figure 6A).

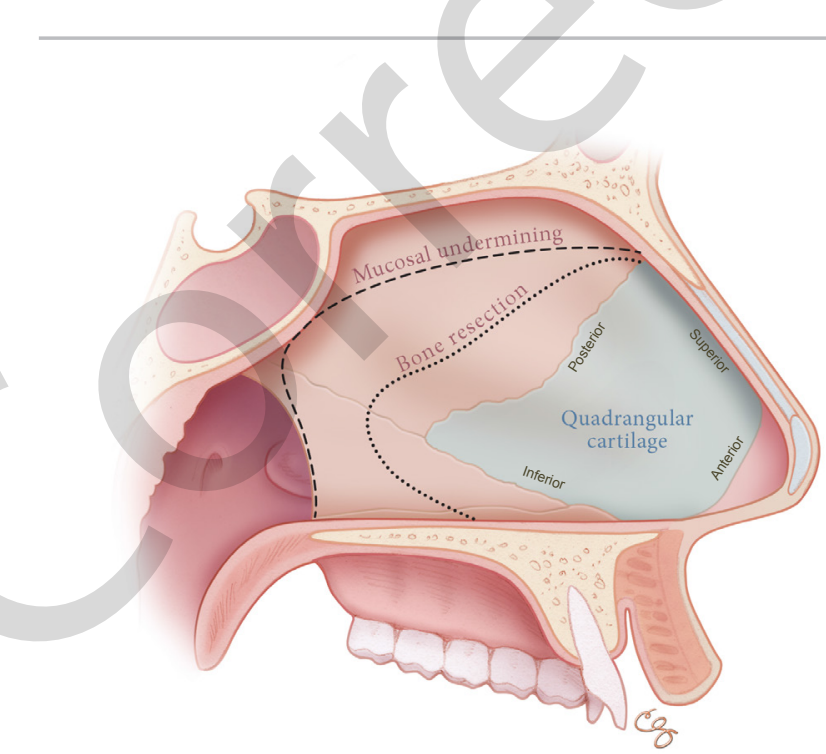

Figure 1. Main steps of septoplasty.

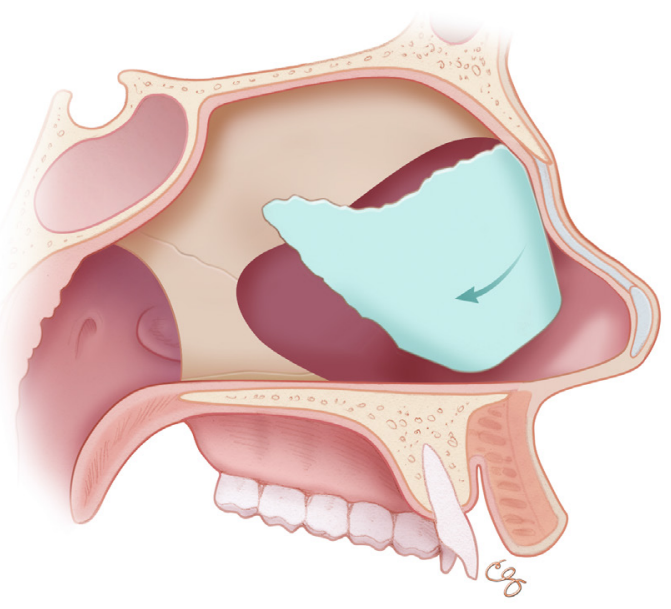

Figure 2. Saddling of the middle vault of the dorsum after disarticulation of the quadrangular cartilage. 
Step 2: Disarticulation of the septolateral unit from under the apex of the bony piriform aperture (Figure 5):

- $\quad$ Either via the internal route with two inter-cartilaginous incisions, or via the external route with one columellar incision, both enabling complete subcutaneous dissection of the nasal dorsum; the procedure via the internal route may benefit of successive endoscopic check-up

- Identification of the suture between the bony and cartilaginous nasal pyramid by palpation using a rigid instrument

- Incision of the soft tissue covering this suture, first laterally on the ascending process of the maxillary bones, then medially at the tip of the nasal bones

- Elevation of the periostium over the bony pyramid to the nasion to expose the bony hump from above

- Disarticulation of the septolateral unit by passing a smooth elevator under the bony margin of the piriform aperture, first laterally under the ascending process and then medially under the nasal bones: the disarticulation is performed in the sub-perichondrial and extra mucosal plane to expose from below the bone to be resected (Figure $5 \mathrm{~A}$ ).

Step 3: Resection of the bony hump (Figure 5B):

- Either by a standard horizontal osteotomy or by two vertical lateral osteotomies meeting in a triangle at the nasion.

Step 4: Open roof repair:

- Internal, lateral osteotomies with nasal vestibular incisions

- Fracture and mobilization of the bone flanges by impaction and closure of the open roof.

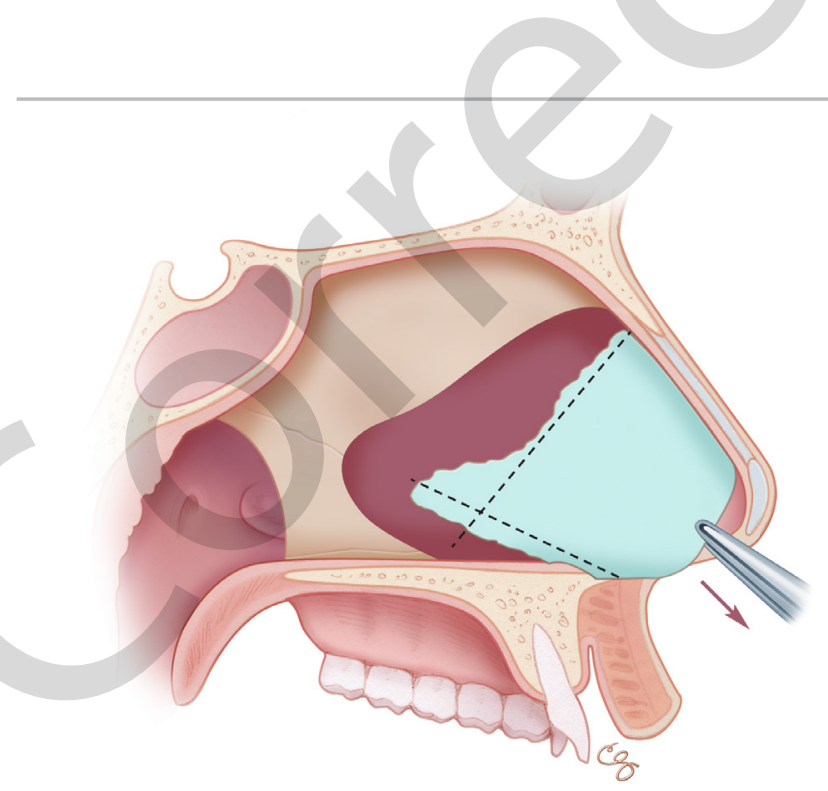

Figure 3. Transcolumellar traction corrects the retrolobular saddling. Dotted line: Resection lines of the quadrangular cartilage.
Step 5: Realignment of the new osteo-cartilaginous dorsum via transcolumellar traction threads:

- Two sutures, one at the antero-inferior and another one at the antero-superior angle of the septal cartilage are placed with two separate, long, resorbable threads

- Each thread is passed through the columellar pocket and exits 1) at the skin of the tip of the nose for the upper thread and 2) at the base of the columella for the lower thread (Figure 6B)

- Traction on these two threads allows, 1) to guide the caudal edge of the septal cartilage into the columellar pocket, 2 ) to correct the retro-lobular saddling and, 3) to reposition the septolateral unit underneath the new bony dorsum; the traction on the threads actually retightens the periostium, which was preserved during the disarticulation procedure and to which the septolateral cartilage remains attached (Figure 5B)

- The traction is maintained by knotting the two transcolu-
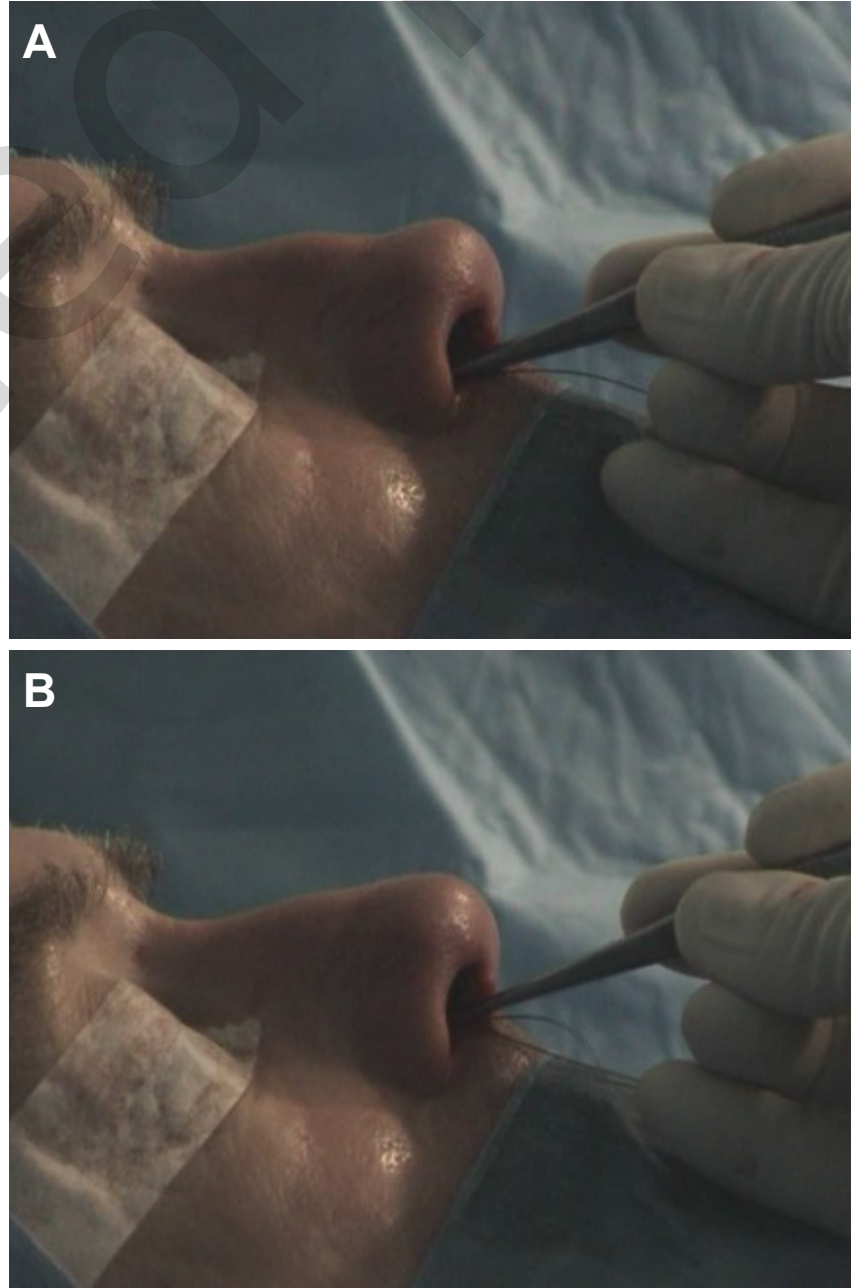

Figure 4. Traction at the antero-inferior angle of the quadrangular cartilage corrects the retro-lobular saddling. A) before traction; B) during traction. 

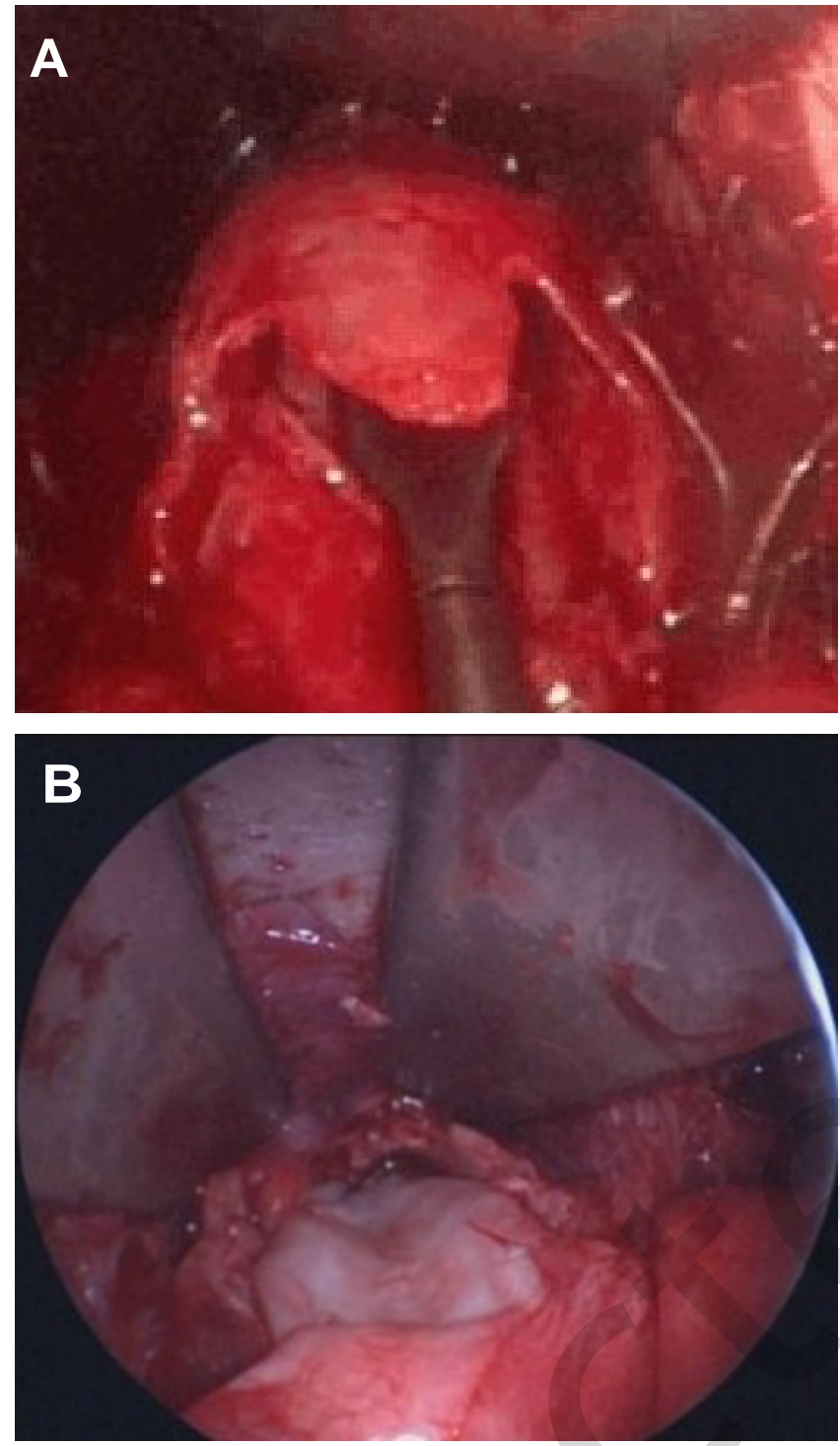

Figure 5. A) Disarticulation of the septolateral cartilage from under the apex of the bony piriform aperture. B) After the bony hump has been resected, the preserved septolateral cartilage stays attached by the perichondrium to the skull base.

mellar threads on a pledget of lint beneath the columella (Figure 6B).

Step 6: Standard dressing:

- Endonasal packing

- External, heat-molded, nasal splint.

\section{Patients}

The study population consisted of adults operated consecutively by the same surgeon (RJ) using the SRD technique between 2003 and 2009. Patients undergoing other techniques (resection of the osteo-cartilaginous hump, Cottle's septorhinoplasty, primary tip rhinoplasty, etc.) were excluded.
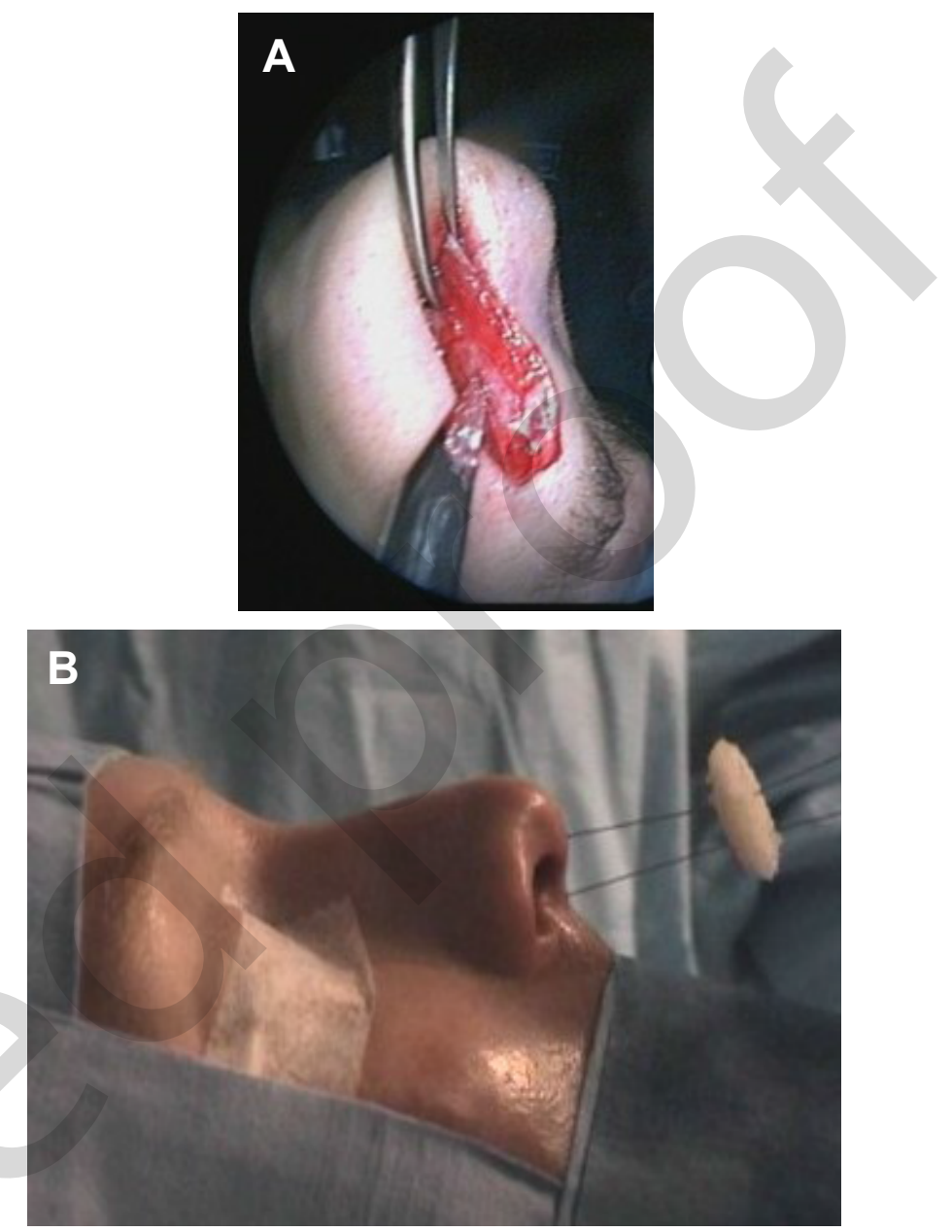

Figure 6. A) Anterior edge resection of the quadrangular cartilage to fit into the columellar pocket. B) Realignment of the new osteo-cartilaginous dorsum via transcolumellar traction threads.

\section{Data collection}

Nasal morphology analysis grid

An analysis grid for nasal deformities was constructed empirically by two investigators (RJ, NB) by reviewing a large series of photographs in the photobank of our department. Patients of this preliminary photograph review were excluded from the study and the two investigators (RJ, NB) were excluded from judging throughout the rest of the study.

Ten items were selected to analyse the morphological aspect of the nose: 1) nasal ridge on frontal and superior view, 2) nasal ridge on profile view, 3) upper lip on profile view ,4) columella on profile view, 5) line between white skin roll and columella on profile view, 6) nasolabial angle on profile view , 7) orbitonasal lines (esthetic dorsal lines) on superior view, 8) the triangle at 

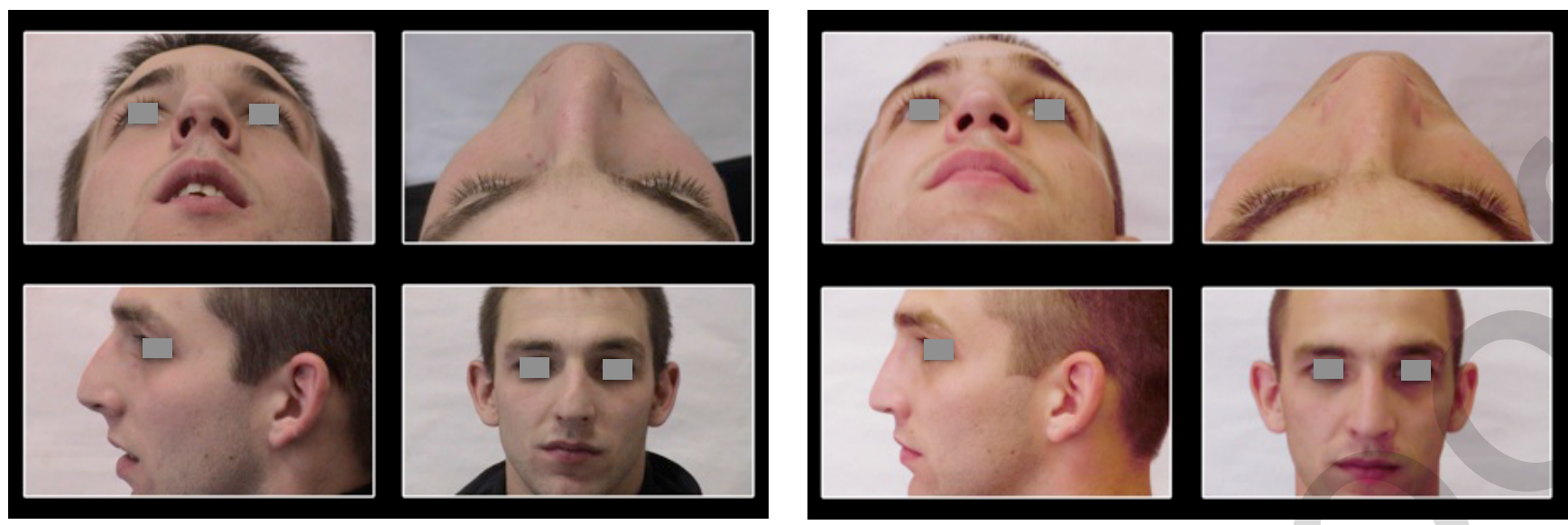

the nose base on inferior view, 9) nostril holes on inferior view and 10) columella on inferior view.

Each of these ten morphological aspects was analyzed using two methods: 1) qualitatively, requiring the observer to classify the deformity by a single choice (box to tick) in a list of pre-established propositions, and 2) quantitatively, assessing the degree of deformity by a score ranging from 0 to 2 ( $0=$ no deformity, 1 = slight deformity, 2 = marked deformity).

The sum of the scores attributed to the ten items gave for each patient an individual global score ranging from 0 to 20 .

The ideal morphology of the nasal pyramid scored $0 / 20$, meaning that:

- the nasal ridge was rectilinear both on frontal, profile and superior view

- the orbitonasal lines were rectilinear and parallel on the median axis

- the nasolabial angle was open at $90^{\circ}$

- the junction between the upper lip and the columella formed a clearly defined angle

- the nasal base was equilateral

- the columella was median

- the nostril holes were symmetric.

In non-ideal nasal morphology, the more numerous and severe the deformities of the nasal pyramid, the higher the score (closer to 20 ).

\section{Photographic plates}

There were four images of each patient: frontal, left profile, basal and helicopter view (a view of the nose from above the face), grouped together on one plate. These four images were taken from the digital patient file, which also contained a right profile and left and right $3 / 4$ views that were not used in this study. Each patient was pictured on two plates: one pre-operative and one post-operative plate with the result at 3 months after surgery (Figure 7 and $8=$ patient photo plates).
Each plate was oriented right/left, then duplicated, then anonymized using a table of random numbers. Information that would help to distinguish between pre- and post-operative photo plates was cut out.

\section{Composition of the panel of judges}

Each pre- and post-operative plate was analysed blindly and independently by six judges, all ENT surgeons: four senior judges practising septorhinoplasties (RB, $\mathrm{PG}, \mathrm{PL}, \mathrm{CL}$ ) and two junior surgeons (HE, RG) who had never conducted septorhinoplasty. Two of the senior judges did not practice in the Hospital Center where the study was carried out (RB, PL). None of the judges performed surgery or surgical monitoring on the study population.

\section{Assessment procedure}

The four series of plates were made available to the judges via internet using Google documents ${ }^{\odot}$.

Images could not be downloaded or modified by the judges and access rights were controlled by the study investigator (NB). As soon as one series was completed, access rights were cancelled and the following series was only available after one week. The judges took the time they needed for assessing each series.

Each judge used an analysis grid for each patient in the form of a paper booklet to record his/her assessments. The anonymizing code number of each plate was recorded in this booklet.

\section{Statistical analyses}

The first step was a descriptive study of the pre- and post-operative morphological aspects in our series.

For each item, the mean frequency of deformities was calculated from the assessment of the six judges, and represented by two bar diagrams for pre- and post-operative aspects, respectively. The second step was to compare the individual pre- and postoperative global scores using Student's paired t-test. The mean 
global pre- and post-operative scores was calculated from the mean of the global scores of the six judges.

The third step was to calculate the percentage of improvement and deterioration of each morphological item after SRD.

To calculate this percentage, we considered that a deformity score dropping from 2 to 0 or from 2 to 1 or from 1 to 0 between pre- and post-operative time-points was an improvement in nasal pyramid morphology (Nota Bene: $0=$ no deformity, $1=$ slight deformity, 2 = marked deformity.)

Conversely, a deformity score increasing from 0 to 1 or from 0 to 2 or from 1 to 2 between pre- and post-operative time-points was considered as a lack of improvement in nasal pyramid morphology.

The percentage of improvement was calculated using the formula:

$\frac{\mathrm{n}(2 \rightarrow 0)+\mathrm{n}(2 \rightarrow 1)+\mathrm{n}(1 \rightarrow 0)}{\Delta 1}$
$\Delta 1=35$ - the number of patients with no pre-operative deformity for the studied criterion (by definition cannot be improved). (Nota bene: 35 is the number of patients in the study)

The percentage in the lack of improvement was calculated using the formula:

$\frac{\mathrm{n}(0 \rightarrow 2)+\mathrm{n}(0 \rightarrow 1)+\mathrm{n}(1 \rightarrow 2)}{\Delta 2}$

$\Delta 2=35$ - the number of patients with marked pre-operative deformity for the studied criterion (by definition cannot deteriorate).

The mean percentages of improvement and deterioration for each morphological item were calculated from the mean of the percentages of the six judges.

The statistical threshold was set at 5\%. Statistical analyses were carried out using SAS software, version 9.1 (SAS Institute Inc., 2002).
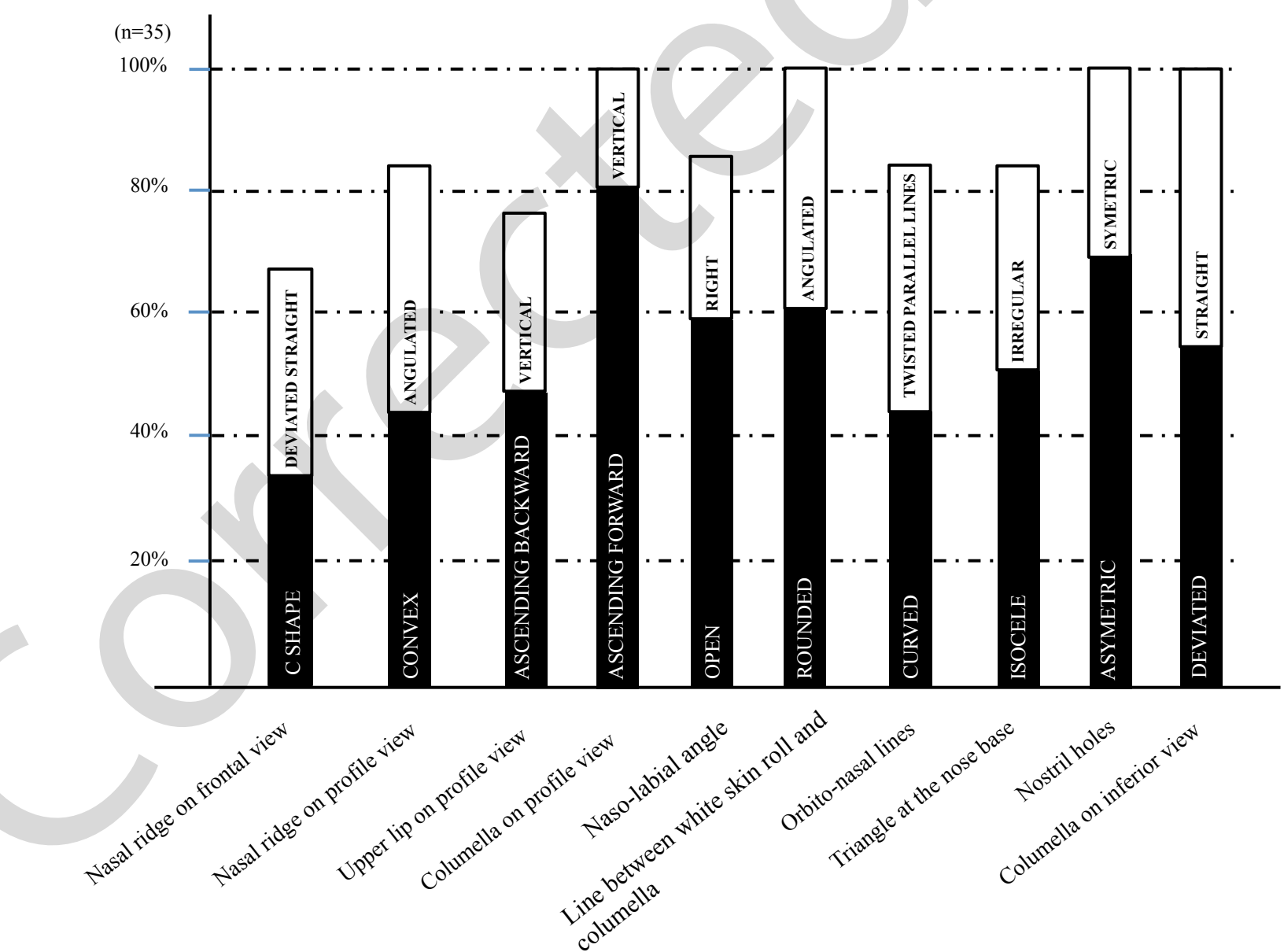

Figure 9. Pre-operative morphological features. 


\section{Results}

Between 2003 and 2009, 185 septorhinoplasties were performed by the same surgeon, 35 of which were SRD. All the patients were Caucasian adults; there were 16 women and 19 men (mean age 31 years; range 18 to 62 years). Amongst these 35 SRD, 33 were performed using the internal approach and two with the external approach.

\section{Nasal morphology analysis}

Pre-operative morphological analysis

The mean frequency of pre-operative morphological features are presented in Figure 9.

In most of the patients, the nose was twisted on the frontal view with a hump on the profile. The upper lip was strongly ascending backwards and connected to the columella, which was ascending forwards, by a round unaesthetic corner. Most of the nasolabial angles were open. The orbitonasal lines (aesthetic dorsal lines) formed two parallel lines but were curved or twisted. The triangle at the base of the nose was either isocele or irregular (asymmetric nostrils). Most of the columella were twisted.

\section{Post-operative nasal morphology}

The mean frequency of post-operative morphological features are presented in Figure 10.

Most patients had a straight nasal crest both on frontal and profile views. The upper lip was slightly ascending backwards or in neutral position and connected to the columella which was slightly ascending forwards or in neutral position. Most of the patients had a right nasolabial angle and a well shaped corner between upper lip and columella. The orbitonasal lines were rectilinear and parallel. The triangle at the base of the nose was either equilateral or isocele with symmetric nostrils. The columella was straight and in a neutral position.

\section{Comparative analysis}

Figure 11 shows the individual changes in pre- and post-operative global scores. The nasal morphology was improved in every
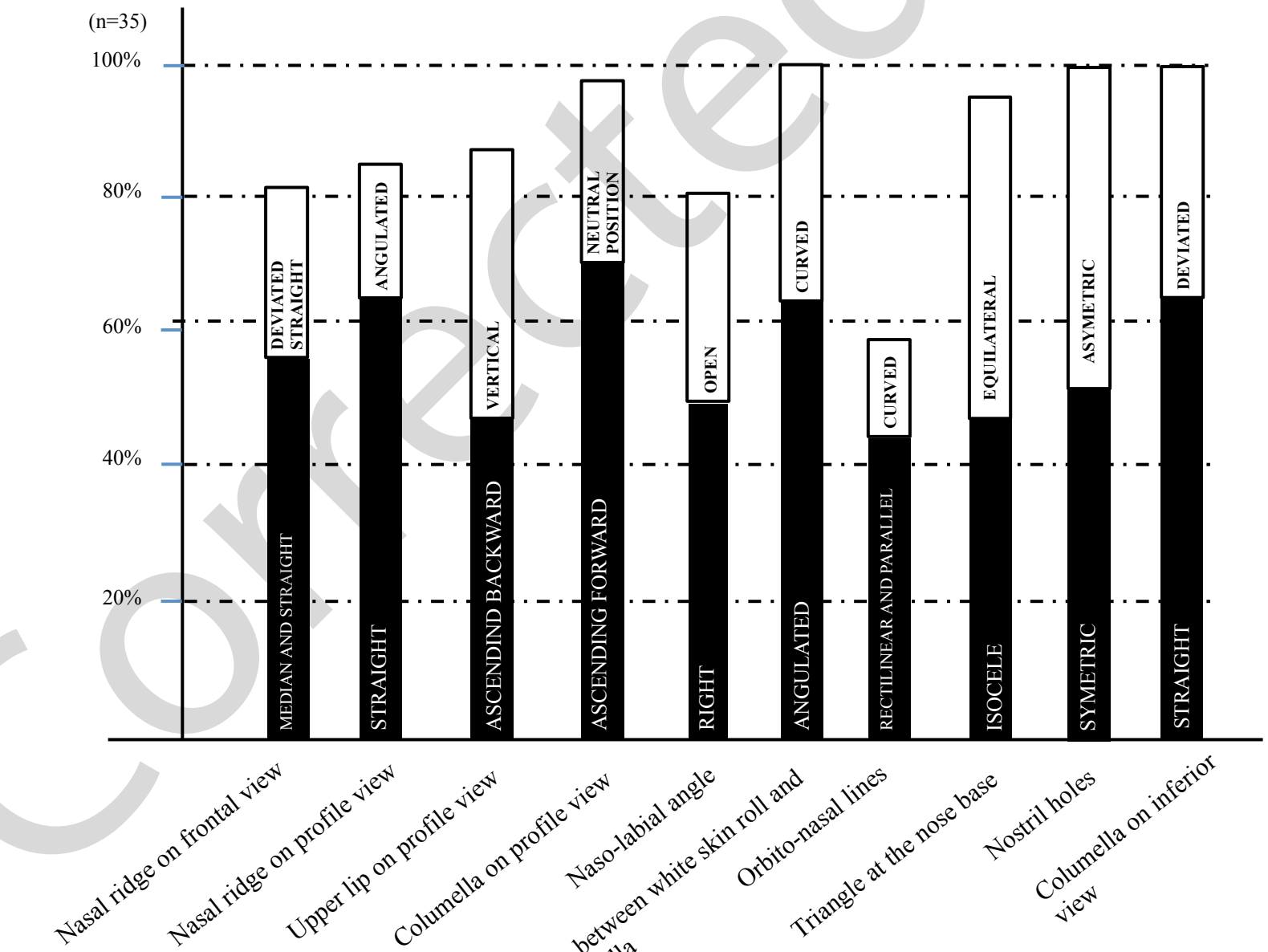

Figure 10. Post-operative morphological features. 


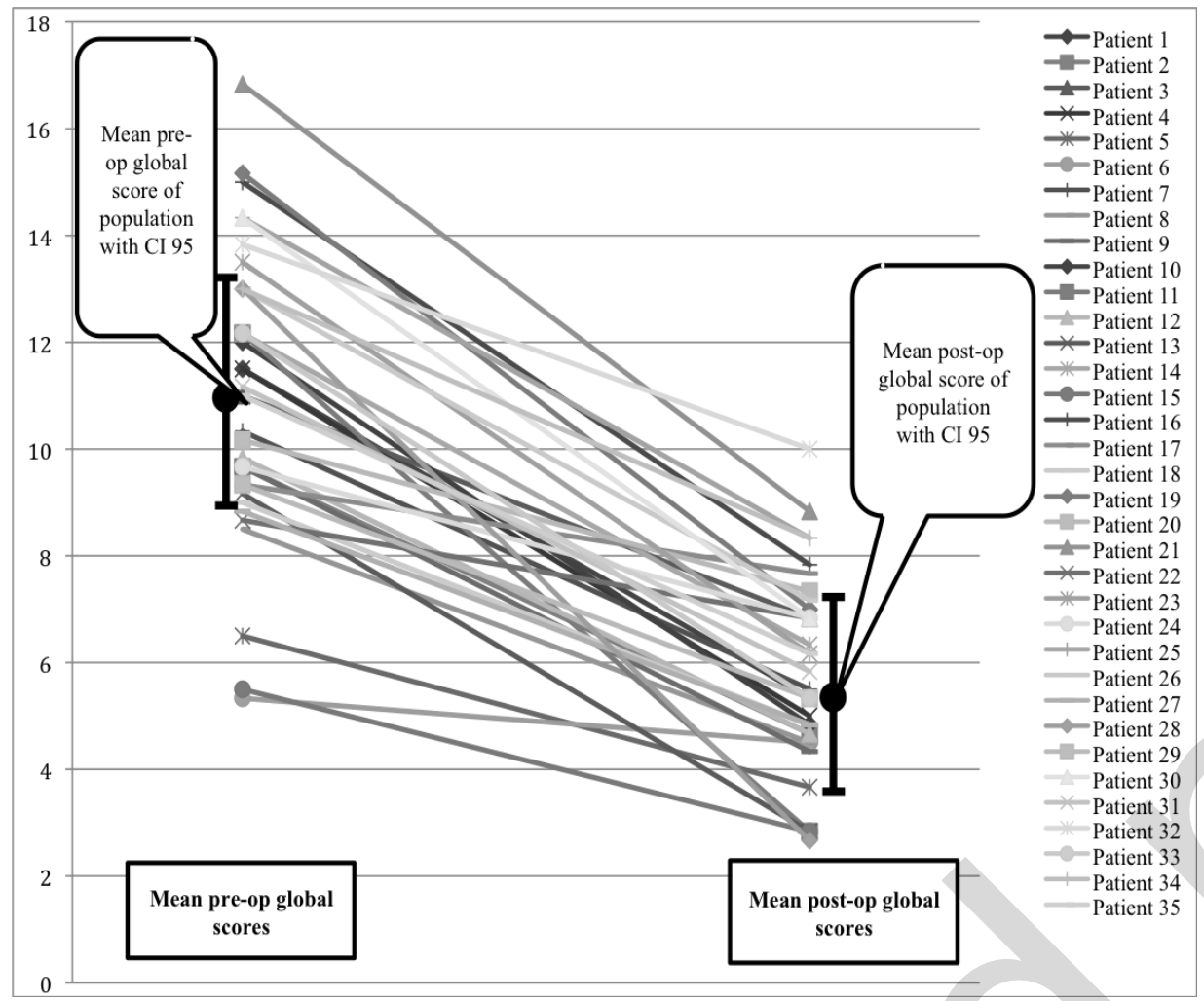

Figure 11. Individual changes in mean pre-and post-operative global scores. $\mathrm{Cl}$ 95: Confidence Intervalle $=95 \%$.

patient. The best improvement went from 13 to 3 , the lowest from 5.3 to 4.5 .

The mean global score of the study population improved from $11.1 \pm 3.6$ pre-operatively to $5.8 \pm 3.0$ post-operatively (mean \pm standard deviation). This difference was statistically significant ( $p<0.0001$ ) and can be expressed as an improvement of $47 \%$ in the mean global score in the study population.

\section{Percentages of improvement and lack of improvement}

Mean percentages of improvement and deterioration for each morphological item are presented in Table 1.

The best corrected morphological feature was the hump on the profile view ( $82 \%$ improvement; $16.7 \%$ lack of improvement and $11.3 \%$ unchanged).

The least corrected and most deteriorated morphological feature was the upper lip position $(49.1 \%$ improvement; $24.3 \%$ lack of improvement and $26.6 \%$ unchanged).

\section{Discussion}

SRD is a novel solution for the morphological correction of crooked noses with humps. Our study shows encouraging preliminary results, which justify adding the technique to our therapeutic arsenal.

This retrospective study is based on the early photographic records obtained 3 months after surgery, which in our practice is the time of first morphological and functional evaluation after septorhinoplasty. This is a very early evaluation in rhinoplasty, which could represent a major drawback in the evaluation of our results. However, if the patient is happy with the result at three months, we do not plan another appointment but ask every patient to feel free coming back again any time in the future if anything would go wrong. Despite the fact that our results were far of being perfect in each case, the improvement was apparently sufficient in most cases for none of these patient felt the need for a revision rhinoplasty. Actually, we did see and photograph again 6 out of the 35 patients between 1 and 5 years after the surgery. This opportunity allowed us to appreciate the stability of their morphological results. Of course, this experience with 6 patients does not allow any generalization, and therefore we have planned another study to check this point. The present study is a first step in the evaluation of the technique, which is based on the only available photographs we had for all the patients operated by SRD, i.e. the pre- and 3 month post-operative photographic records.

The aesthetic results of rhinoplasty procedures are difficult to assess since criteria of evaluation remain highly subjective. Results may be based on patient satisfaction using quality-of-life questionnaires ${ }^{(3)}$. However, these questionnaires do not provide the surgeon with information on the performances or insufficiencies of the technique. We wanted to assess our results as objectively as possible and looked for replacing aesthetic criteria by morphological criteria. Only one morphological analysis grid 
Table 1. Mean pourcentages of improvement and lack of improvement for each morphological items.

\begin{tabular}{|c|c|c|}
\hline Morphological items & $\begin{array}{l}\text { Mean pourecentage of improvement } \\
\text { (min-max of six judges) }\end{array}$ & $\begin{array}{l}\text { Mean pourcentage in lack of improvement } \\
\text { (min-max of six judges) }\end{array}$ \\
\hline PNasal ridge on profile view & $82 \%(70-87)$ & $16,7(4-30)$ \\
\hline $\begin{array}{l}\text { Orbito-nasal lines on superior view } \\
\text { (Aesthetics dorsal lines) }\end{array}$ & $74,3(60-90)$ & $14,4(0-43)$ \\
\hline Columella on inferior view & $72,4(47-85)$ & $12(3-19)$ \\
\hline Line between white skin roll and columella & $69,9(67-86)$ & $18,9(7-21)$ \\
\hline Nasal ridge on frontal view & $64,3(54-80)$ & $14,6(0-17)$ \\
\hline Triangle at the nose base on the inferior view & $61,2(53-74)$ & $18,2(4-27)$ \\
\hline Nostril holes on inferior view & $61(55-68)$ & $14,6(12-17)$ \\
\hline Columella on profile view & $53,6(37-63)$ & $11,1(4-19)$ \\
\hline Upper lip on profile view & $49,1(38-67)$ & $24,3(12-36)$ \\
\hline
\end{tabular}

was found in the literature but did not meet our objectives ${ }^{(4)}$. Therefore, we designed a new one on the base of 10 criteria defining our ideal morphology of the nasal pyramid and looked for the possible dysmorphies of each of these criteria by checking in our rhinoplasty databank. These pictures of patients were not included in the study.

The objective of our study was, however, not to design a formal tool for assessing rhinoplasty results, but just to assess, as objectively as possible, the preliminary results of the SRD technique with a sample of 35 patients on whom the technique had been performed. Since the sample was small, we tried to improve the evaluation by asking a panel of independant judges to individually analyze the patient's photographs. In our opinion, only surgeons had the expertise required to perform detailed and accurate morphological analysis, but the panel was chosen to have a large scale of expertise: 4 judges were senior ENT and 2 judges were junior ENT.

The use of Google documents ${ }^{\circ}$ was an effective and attractive method of making the photographic plates available to each panel member throughout the duration of the study. The plates remained anonymous and patient anonymity was complied with thanks to an access code controlled by the investigator.

The panel assessment showed individual improvement in the mean global score (Figure 11), but detailed analysis of each morphological feature did not find any ideal correction for a given individual. This reflects the reality of surgical results which cannot be perfect in all aspects ${ }^{(4,8)}$.

SRD was found to be effective in correcting $82 \%$ of bony humps
(Table 1), either convex (42\%) or angulated (39\%) (Figure 9), resulting in a straight nasal ridge in $63 \%$ of patients (Figure 10) without any risk of over correction.

Correction of crooked noses is considered one of the most difficult septo-pyramidal surgical procedures ${ }^{(9)}$ and several techniques have been proposed ${ }^{(10-13)}$. SRD improves frontally, deviated, nasal crests by $64.3 \%$ (Table 1 ), resulting in the expected correction in $57 \%$ of patients (Figure 10 ). This probably also contributes to the improvement observed in dorsal aesthetic lines (74.3\%).

SRD also revealed interesting results in the correction of the junction between the upper lip and columella in $70 \%$ of patients, without any need to touch the anterior nasal crest or the premaxilla. This transformation of the nasolabial angle seems to result of a complex mechanism of relaxation of the lower $1 / 3$ of the nose combined with a shortening of the inferior and posterior edges of the septum with a movement of rotation upwards and backwards of the tip of the nose after realignment of the septo-lateral unit under the new bony dorsum by traction on threads.

Whilst $65 \%$ of nostrils were asymmetric before surgery, $52 \%$ had become symmetric afterwards. This improved symmetry underlines the correction of the underlying septal deviations. Although our study did not aim for functional results, we would like to highlight that 30/35 patients claimed three months after surgery that their nose breathing was improved. This is probably the result of Cottle's septoplasty as used in the SRD technique. Various septoplasty techniques have been described ${ }^{(14)}$, but it is very difficult to compare and assess their respective functional 
outcomes ${ }^{(15-17)}$. We regulary use Cottle's technique to correct septal deviations and this technique prooves regularly to be very effective in terms of functional results. We must, however, precise that when septal deviation is associated with asymmetric hypertrophy of the lower turbinates, partial inferior turbinectomy is performed to replace the nasal septum in the midline plane and to make the two lower nasal air channels symmetrical.

The major risk of Cottle's septoplasty technique is post-nasal tip saddling. After disarticulation of the quadrangular cartilage from the vomer and perpendicular plate, saddling is more or less constantly observed during the procedure. We have learned some 25 years ago from one of our teachers that this pitfall could be corrected by the use of trancolumellar traction threads. We have used this trick over the years as a regular routine without having a look in the literature. We actually did not find any literature and recently asked our retired teacher who was the father of this trick, but he did not remember from where he had himself learned it. This trick works very well in septoplasty and we have just extended its application to the SRD technique. The explanation we have about the effectiveness of this trick is that after its disarticulation from the bony nose, the septolateral cartilage remains attached through the periosteum (Figure5B) to the cranial base ${ }^{(18)}$; any traction on the anterior edge of the quadrangular cartilage will then stretch the periosteum in line with the septolateral cartilage (Figure 6B).

Most patients (33/35) were operated via the internal route since no tip surgery was planned or performed. For two patients, nasal tip surgery was necessary and performed via an open approach. We then realized that the SRD technique was far more easy via an open approach. Most patients today are operated via the external route, which allows for more accurate intra-operative analysis of the anatomical deformities, better visual control of the disarticulation procedure between bony and cartilaginous nose, easier correction of the bony hump and simultaneous work on the nasal tip. SRD via the external route allows to operate on the three levels of the nasal pyramid as a well codified order: 1) the septo-triangular unit, 2) the bony nose, 3 ) the lower $1 / 3$ of the nose.

Complications and drawbacks of the procedure seem exceptional in our experience. No CSF leak or no disturbance of smell has been reported despite the large undermining of the septal mucosa and resection of the perpendicular plate. The risk of completely freeing the septal cartilage does exist, but none of the patients in this study had such a complication. Such a complication has been encountered in septoplasty procedures when the cartilage is severely deformed or altered, but the extracorporal septoplasty ${ }^{(19)}$ is the way to solve the problem.

To conclude, this paper reports our initial experience with a novel technique referred to as septorhinoplasty by disarticulation, a technique which combines Joseph's aesthetic preoccupations with Cottle's septoplasty functional results. These early results are encouraging us to further develop the technique.

\section{Authorship contribution}

Design of the study, analysis and interpretation, writing of the manuscript: NB, CB, RJ; Data collection: $R B, H E, P G, R G, P L, C L$

\section{Conflict of interest}

No conflict of interest.

\section{References}

1. Joseph J. Intranasale Nasenhöckerabtragung. Berl. Klin. Wochenschr. 1904; 650.

2. Cottle $\mathrm{MH}$, Loring RM. Corrective surgery of the external nasal pyramid and the nasa septum for restoration of normal physiology. Eye Ear Nose Throat Mon. 1947; 26 207-212.

3. Alsarraf R, Larrabee WF. Outcomes research in facial plastic surgery. Arch Facial Plast Surg. 2001; $3: 7$

4. Ching S, Thoma A, McCabe RE, Antony MM Measuring outcomes in aesthetic surgery: a comprehensive review of the literature. Plast Reconstr Surg 2003; 111: 469-480.

5. E.Dale Collins. Measuring Outcomes in Aesthetic Surgery: A Comprehensive Review of the Literature. Plast Reconstr Surg
2003; 111: 481-482.

6. Anderson JR. A scale for evaluating results of rhinoplasty. Arch Otolaryngol . 1985; 111 : 520-523.

7. Rhee JS, McMullin BT. Measuring outcomes in facial plastic surgery: a decade of progress. Curr Opin Otolaryngol Head Neck Surg. 2008; 16: 387-393.

8. Koch GG, Landis JR, Freeman JL, Freeman DH, Lehnen RC. A general methodology for the analysis of experiments with repeated measurement of categorical data. Biometrics. 1977; 33: 133-158.

9. Sjödén GO, Movin T, Güntner $P$, Aspelin $P$, Ahrengart L, Ersmark H, Sperber A. Poor reproducibility of classification of proximal humeral fractures. Additional CT of minor value. Acta Orthop Scand. 1997; 68: 239242.
10. Okur E, Yildirim I, Aydogan B, Akif Kilic M. Outcome of surgery for crooked nose: an objective method of evaluation. Aesthetic Plast Surg 2004;28(4):203-207.

11. Stepnick D, Guyuron B. Surgical treatment of the crooked nose. Clin Plast Surg. 2010; 37: 313-325.

12. Constantian MB. An algorithm for correcting the asymmetrical nose. Plast Reconstr Surg. 1989; 83: 801-811.

13. Byrd HS, Salomon J, Flood J. Correction of the crooked nose. Plast Reconstr Surg. 1998; 102: 2148-2157.

14. Rohrich RJ, Gunter JP, Deuber MA, Adams WP. The deviated nose: optimizing results using a simplified classification and algorithmic approach. Plast Reconstr Surg. 2002; 110: 1509-1525.

15. Pontius AT, Leach JL. New techniques for 
management of the crooked nose. Arch Facial Plast Surg 2004; 6: 263-266.

16. Fettman N, Sanford T, Sindwani R. Surgical management of the deviated septum: techniques in septoplasty. Otolaryngol Clin North Am. 2009; 42: 241-252.

17. Dinis PB, Haider H. Septoplasty: long-term evaluation of results. Am J Otolaryngol. 2002; 23: 85-90.

18. Jankowski R. The evo-devo origin of the nose, anterior skull base and midface. Paris: Springer Verlag, 2013. ISBN 978-2-8178-
0421-7.

19. Gubisch W. Extracorporeal septoplasty for the markedly deviated septum. Arch Facial Plast Surg. 2005; 7: 218-226.
Roger Jankowski

ORL Dept Hôpital Central

54000 Nancy

France

Tel : +33-3-8385 1152

Fax : +33-3-8385 2258

Email : r.jankowski@chu-nancy.fr 